\title{
Sobre Abraham Willemsens y el éxito del tema de Moisés salvado de las aguas dentro de su producción
}

\author{
About Abraham Willemsens and the Fortune of the Subject \\ The Finding of Moses in his Production
}

\begin{abstract}
Matías Díaz Padrón ${ }^{1}$
Académie Royale d'Archéologie et d'Histoire de 1'Art de Belgique

Instituto Moll. Centro de investigación en pintura flamenca
\end{abstract}

Resumen: En este artículo se estudian varios cobres de Moisés salvado de las aguas del pintor flamenco Abraham Willemsens, artista largo tiempo confundido con el Monogramista AW y del que damos las claves para su individualización. También se sugiere identificar al Monogramista AW con Anthonis Willemsen, activo en Amberes de 1649 a 1691 . Esta composición de Moisés salvado de las aguas está inspirada en modelos de Rubens y sus seguidores. El resultado tuvo gran éxito y fue repetida en numerosas ocasiones por otros artistas.

Palabras clave: Abraham Willemsens; Anthonis Willemsen; Monogramista AW; Erasmus Quellinus; Theodor Boeyermans, Willem van Herp; Flandes; siglo XVII; pintura de género.

Abstract: Several coppers with The Finding of Moses by the Flemish painter Abraham Willemsens give the key to portray his style, very different from the Monogrammist AW with whom was long time mixed-up. This Monogrammist AW is also linked here to the painter Anthonis Willemsen, active in Anvers from 1649 to 1691 . The Finding of Moses composition is inspired by models of Rubens and his followers. That scene had very success and was repeated by different artists.

Keywords: Abraham Willemsens; Anthonis Willemsen; Monogrammist AW; Erasmus Quellinus; Theodor Boeyermans; Willem van Herp; Flanders; $17^{\text {th }}$ century; genre painting.

1 (๑) https://orcid.org/0000-0002-5137-7583

(c) 2021 Philostrato. Revista de Historia y Arte 


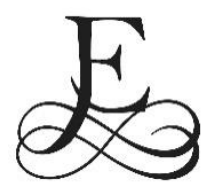

I cobre con la historia de Moisés de notable calidad que restituimos a Abraham Willemsens, procede del coleccionismo privado de Madrid $^{2}(70 \times 86 \mathrm{~cm})$, (Fig. 1). La obra, sin consideración crítica hasta ahora, tiene especial interés para nosotros por representar las características de este artista controvertido, que nos sentimos inclinados a colocar en el capítulo de lo que se ha dado en llamar pintura de género. Una temática, rica y fecunda en Flandes, que es opuesta a la espectacular concepción plástica y compositiva de Rubens, lo que no impide contactos y recursos tomados de su obra. De este tipo de pinturas hay una sobrada proyección en España, donde los pintores de género encontraron una fiel clientela ${ }^{3}$.

El tema elegido de la historia sagrada tiene más intención de alegrar la vista que de exaltar el sentimiento religioso. Es esta la función visual de estas atractivas pinturas. El pintor toma la secuencia que siguió al mandato de Herodes de matar a los niños nacidos en aquellos días: "Una mujer tiró un canastillo con betún y brea, y colocó allí un niño y lo puso a la orilla del río. La hija del Faraón bajó a bañarse con sus doncellas, allí vio la canastilla y mandó traerla a una de sus doncellas. Allí estaba un niño llorando [...]" (Éxodo, 1:22).

Aquí el niño en la canastilla lo recoge una joven doncella que se adelanta a la comitiva con la hija del Faraón aproximándose a la orilla del río para bañarse. Un cortejo con ecos visuales de la tradición clásica, de ahí la mesura, la dignidad y la belleza. Cierra la escena un montículo con vegetación en el centro, a la derecha se abre el espacio a un palacio en el fondo y a la izquierda al valle que abre el río. Una escultura clásica femenina sobre un plinto a la derecha cierra la escena, e introduce al espectador al dirigirle su mirada. La luz baña el fondo y a las doncellas atentas al singular hallazgo. El suceso es fiel a la narrativa de la Biblia, salvo por incluir el animado diálogo entre las mujeres y el cortejo propio de la corte. Tanto la composición como el contenido responden a una visión de mayor aliento que la de la historia bíblica. Esto motiva a sospechar en una inspiración más ambiciosa. Así vemos

\footnotetext{
${ }^{2}$ La obra ha sido recientemente restaurada y sometida a diversos exámenes químicos que han permitido identificar en las micromuestras un adhesivo en una capa interna sobre el soporte, impregnado por la migración del cobre, lo que le dota de un tono verdoso en la sección transversal. Sobre este adhesivo aparece una capa de color grisáceo a modo de imprimación. A continuación, capas de pintura al óleo con materiales de amplio uso. Especialmente el amarillo de plomo y el estaño limitado. Véase apéndice documental.

${ }^{3}$ Sobre las obras para el mercado que realiza Abraham Willemsens para la firma Musson-Fourmenois, veáse: E. Duverger, "Nieuwe gegevens betreffende de kunsthandel van Matthijs Musson en Maria Fourmenois te Antwerpen tussen 1633 en 1681", Gentse Bijdragen tot de Kunstgeschiedenis en de Oudheidkunde, 21, (1968), pp. 211-228; Neil de Marchi y Hans J. van Miegroet, "Uncertainty, family ties and derivative painting in seventeenth-century Antwerp", en Family Ties. Art Productions and Kinschip Patterns in the Early Modern Low Countries, ed. K. Brosens, L. Kelchtermans y K. van der Stighelen, (Turnhout: Brepols, 2012), pp. 67-68.
} 


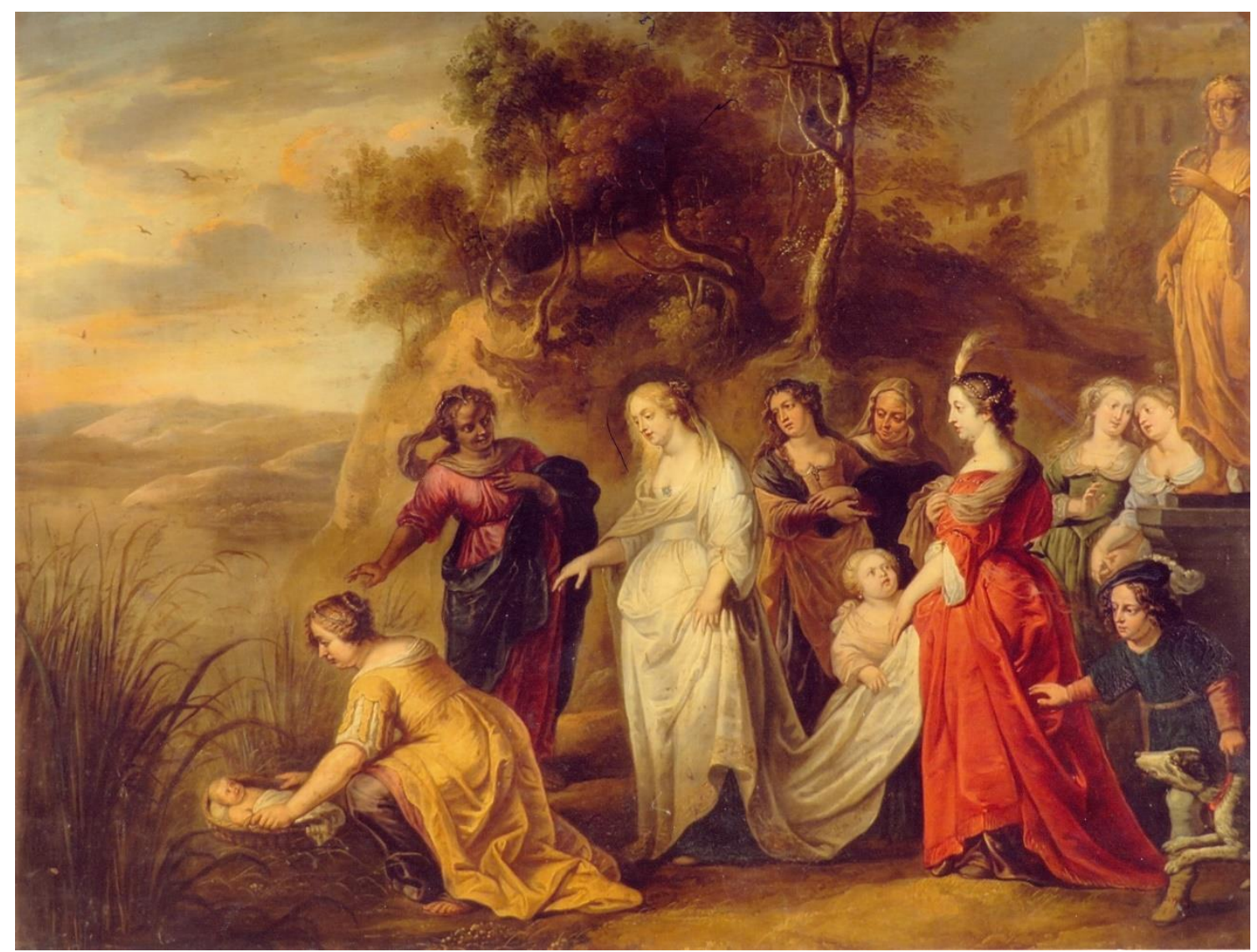

Fig. 1. Abraham Willemsens, Moisés salvado de las aguas del Nilo. (Óleo sobre cobre, 70 x 86 cm.). Colección privada, Madrid. () Foto autor

signos afines a las propuestas de Rubens. La belleza se impone en los modelos y gestos de todas las mujeres, salvo los pajes que se vuelven atentos para ocuparse de los vestidos de las damas y sostener al perro inquieto por la aparición del niño en la canastilla. Todo sigue una feliz composición a ritmo del acontecimiento.

Nos adelantamos a fijar la atención del rostro y la mirada de la mujer con los brazos cruzados en el segundo plano detrás de la hija del Faraón. Es un modelo idéntico al que repite en la musa sentada tañendo el laúd en Minerva visitando las Musas de colección privada (o/c., 58,42 x 109,22 cm.), (Fig. 2), obra firmada por el pintor ${ }^{4}$. Un rostro que encontramos en más de una ocasión en las obras de este artista.

Esta escena del Encuentro de Minerva con las musas es para nosotros fundamental para el estudio del pintor. Define sus características para reunir su producción, que ha estado confundida con el conocido como el Monogra-

\footnotetext{
${ }^{4}$ Antes en la colección M. F. Massot Newpont-Wellin. Christie's, (29-03-1968, n. ${ }^{\circ}$ 70.) No se reprodujo en esta venta.

Anotamos que Abraham Willemsens copió con fidelidad la composición de Hendrick van Balen a través del original del Museo de Amberes (inv. n.0 957) firmado en colaboración con Jan Brueghel "el viejo" y Joos de Momper; Bettina Werche, Hendrick van Balen (1575-1632). Ein Antwerpener Kabinettbildmaler de Rubenszeit, (Belgium: Brepols, 2004), p. 175, n. ${ }^{\circ}$ A.103.
} 


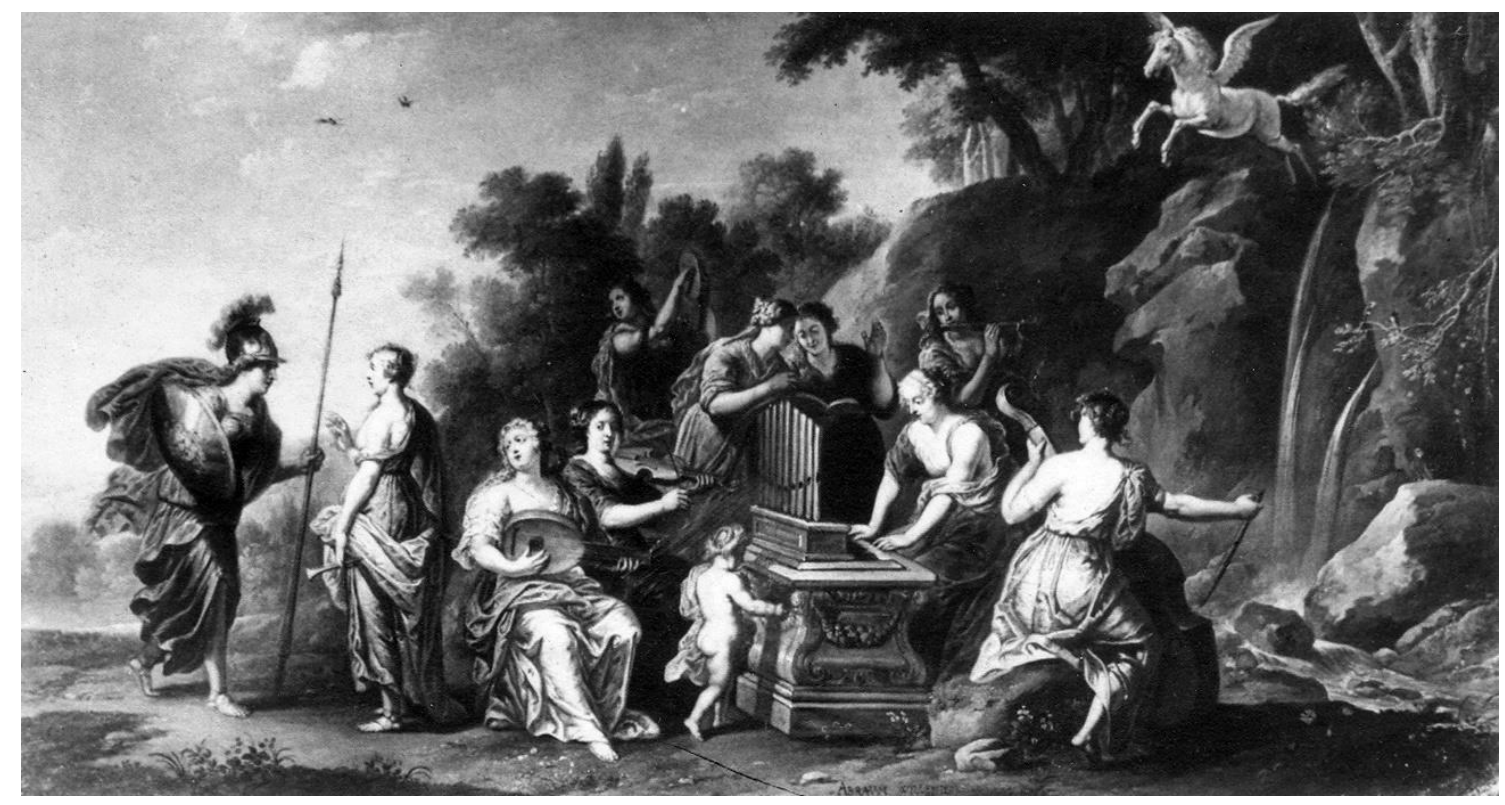

Fig. 2. Abraham Willemsens, Minerva visitando a las Musas en el Helicón. (Óleo sobre cobre, 58,42 x 109,22cm).

Colección privada. (C) Foto autor

mista AW y el Maestro de los Capillos. Es comprensible entender que en un primer momento las obras firmadas con las iniciales AW se identificaran con el pintor Abraham Willensems por la correspondencia de las siglas ${ }^{5}$. Sin embargo, el análisis detenido de la pintura del Encuentro de Minerva con las musas y otras obras firmadas con el monograma AW llevan a apreciar distintos lenguajes visuales. De hecho, en 2005, me aventuré a vincular este monograma AW con otro pintor con el que coincidían las iniciales y activo en Amberes entre 1649 y 1691: Anthonis Willemsens ${ }^{6}$. Su producción es desconocida, quizá por esta confusión de monogramas y artistas, pero sí estaba registrado en la guilda de pintores y contaba con un importante taller, como se desprende del reparto que hace en su testamento de los dibujos, bocetos, modelos en yeso y grabados entre sus dos hijos y su hermano7. Sanzsalazar en 2008 aporta otra nueva obra firmada a la producción de Abraham Willemsens y ordena toda esta amalgama de estilos y bibliografía dispar sobre el autor diferenciando tres personalidades diferentes ${ }^{8}$, pues tam-

\footnotetext{
${ }^{5}$ Enrique Valdivieso, "Dos pinturas de Abraham Willemsens en el Museo del Prado y otras obras de este pintor en España", Boletín del Museo del Prado, VII, 21, (1986), pp. 166-172; M. Roethlisberger, "Le peintre Abraham Willemsens", Jaarboek van het Koninklijk Museum voor Schone Kunsten Antwerpen (1988), pp. 253-259.

${ }^{6}$ Sobre este asunto y las características del Monogramista AW véase Matías Díaz Padrón, "Tres pinturas flamencas identificadas en México", Boletín del Seminario de Arte y Arqueología, (BSAA arte), LXXI, (2005), pp. 163-173 (esp. 168-169)

7 Ph. Rombouts y Th. Van Lerius, De Liggeren en Andere Historische Archieven, II, (Gravenhage: Martinus Nijhoff, 1872), pp. 205, 210 y 413. Erik Duverger, Antwerpse Kunstinventarissen uit de Zeventiende Eeuw, Fontes Historiae Artis Neerlandicae, 12, (Brussel: Koninklijke Vlaamse Academie van België voor Wetenschappen en Kunsten, 2002), pp. 106-107.

8 Jahel Sanzsalazar, "Identificada una pintura de Abraham Willemsens con atribución a Willem van Herp", Boletín del Museo de Instituto Camón Aznar, 101, (2008), pp. 260-261.
} 


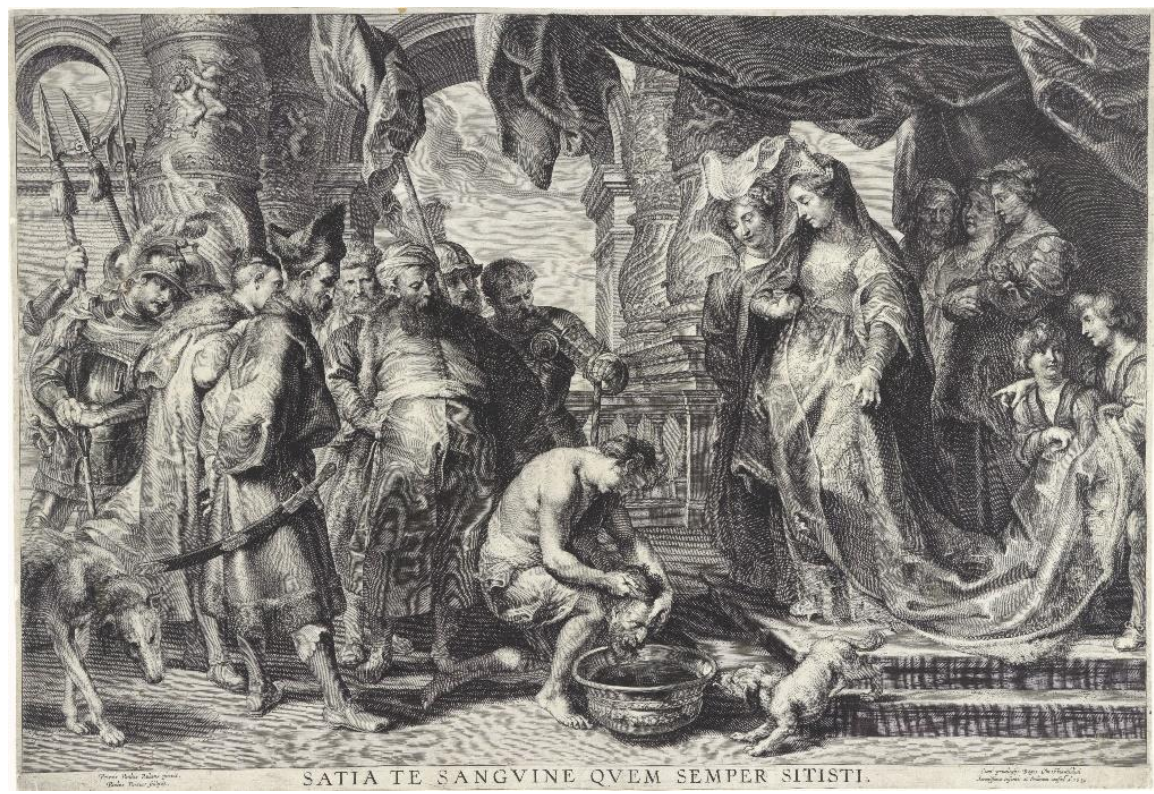

Fig. 3. Paulus Pontius siguiendo a Pedro Pablo Rubens, La venganza de Tomiris, 1630. (Grabado sobre papel). () Rijksmuseum, Ámsterdam (N. ${ }^{\circ}$ RP-P-OB-70.057).

bién hay que desglosar al denominado Maestro de los capillos que en 1991 Martin propuso vincular con Abraham Willemsens ${ }^{9}$, y que al igual que Sanzsalazar, De Marchi y Van Miegroet, rechazan ${ }^{10}$.

Tras este inciso sobre la personalidad en la que nos centramos, volvemos al cobre origen de estas líneas. Nos adelantamos a advertir la similitud del paisaje, así como la pose de la protagonista en el centro, con la musa que se adelanta a dialogar con la diosa del cobre firmado. Tanto el juego de los volúmenes como los gestos se repiten en la joven vestida de rojo con la mano al pecho detrás de la princesa del cobre que tratamos. La sugestión de Rubens se toma del lienzo de La cabeza de Ciro entregada a la reina Tomiris del Museo de Bellas Artes de Boston (inv. n. 0 41.40). Es la misma distinción y marcha cadenciosa con la pose de la princesa en perfil y las doncellas que la siguen, incluso con los niños y detalles recogiendo los mantos. Muy posiblemente Abraham Willemsens utilizó el grabado de Paulus Pontius siguiendo el lienzo de Rubens ${ }^{11}$ (Fig. 3), como referente. Tampoco hay que desestimar la influencia del grabado de Nicolaes Ryckmans ${ }^{12}$ del lienzo de Aquiles descubierto por Ulises y Diomedes del Museo del Prado ( $\mathrm{n} .{ }^{\circ}$ inv. P001661) de Rubens y Anton van Dyck ${ }^{13}$. (Fig. 4) De hecho, la joven arrodillada recogiendo las armas le sirvió para la doncella que toma la canas-

\footnotetext{
${ }^{9}$ Gregory Martin, "The Maître aux Béguins. A proposed identification", Apollo, CXXXIII, 348, (1991), pp. 112-115; Gregory Martin, "Abraham Willemsens (again). More news of attributions in Flemish painting", Apollo, CXXXXII, 372, (1993), pp. 97-102.

${ }^{10}$ De Marchi y Van Miegroet, "Uncertainty, family ties", p. 67.

${ }^{11}$ Rijksmuseum (n.0 RP-P-OB-70.057).

12 Metropolitan Museum of Art ( $n^{\circ} 51.501 .7693$ ).

13 Matías Díaz Padrón, Van Dyck en España, II, (Madrid: Editorial Prensa Ibérica, 2012), pp. 432-439, n. 047.
} 


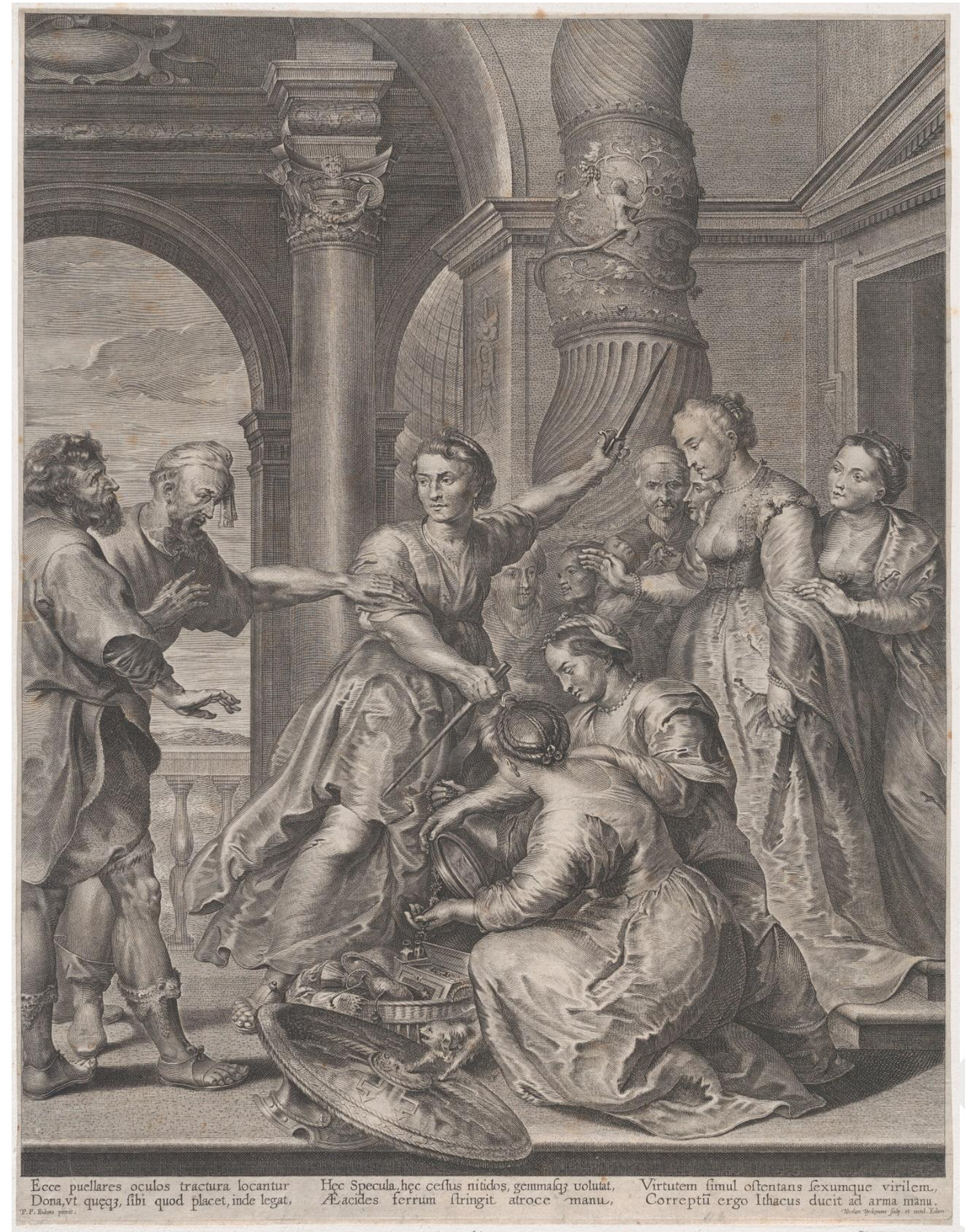

Fig. 4. Nicolaes Ryckmans siguiendo a Pedro Pablo Rubens y Anton van Dyck, Aquiles y las hijas de Licomedes, ca. 1620-1626. (Grabado sobre papel). (C) Metropolitan Museum of Art, Nueva York (inv. n. ${ }^{\circ}$ 51.501.7693).

tilla del río en el cobre que se estudia. Finalmente, se ven sugerencias del grabado de Schelte à Bolswert con la historia de la Continencia de Escipión de Rubens ${ }^{14}$. (Fig. 5) El lado derecho lo ocupa la joven que se ofrece al general romano con el manto y nicho con escultura. En fin, es fácil ver la dependencia

${ }^{14}$ National Gallery of Art, Washington (inv. no 1974.53.32). 


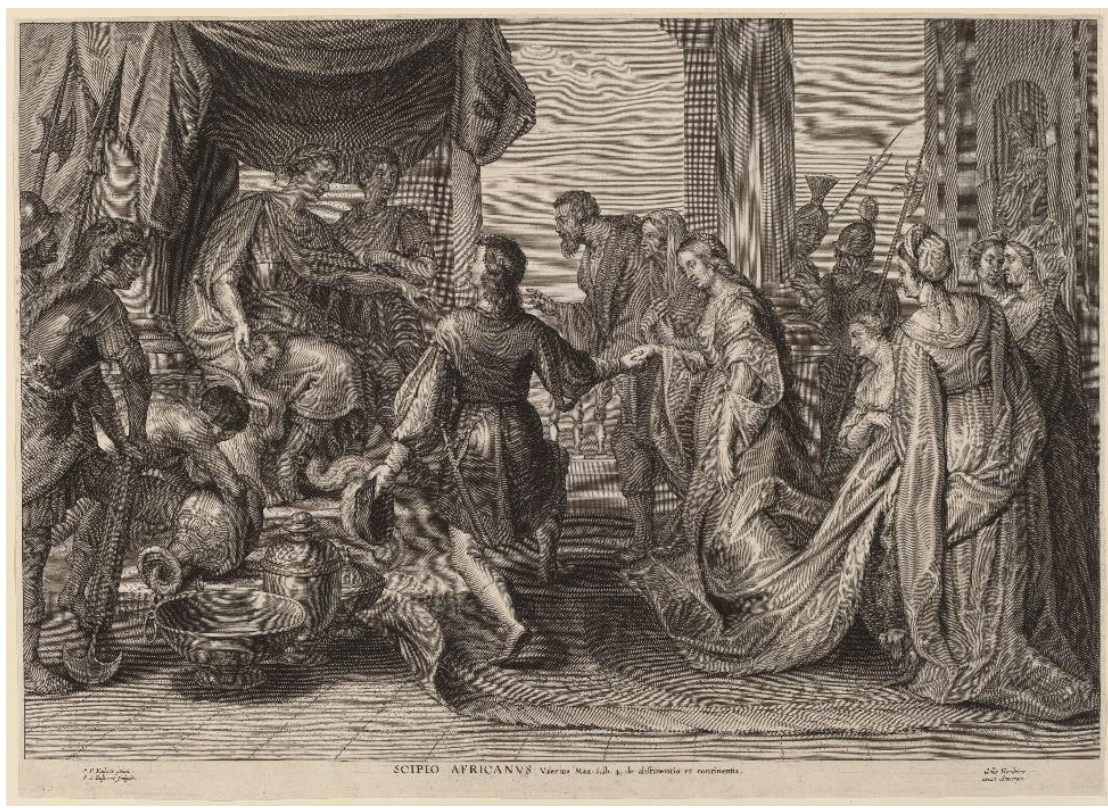

Fig. 5. Schelte A. Bolswert siguiendo a Pedro Pablo Rubens, Escipión el africano. (Grabado sobre papel). (C) Courtesy National Gallery of Art, Washington D. C. (inv. nº 1974.53.32).

tanto directa como indirecta de las composiciones de Rubens en esta obra de Willensens. Su estancia en el taller parisino del flamenco Jean Picart, haciendo copias de otros autores ${ }^{15}$, explica esta dependencia de modelos ajenos y su combinación en nuevas propuestas.

Por fortuna, localizamos la fuente más directa para esta escena de Moisés salvado de las aguas en la escena de la Continencia de Escipión de Erasmus Quellinus (o/c. $255 \times 108 \mathrm{~cm})^{16}$. (Fig. 6) Abraham Willemsens omitió al general romano que está de pie en el trono, pero tomó al joven arrodillado, que pasó a servir a la mujer recogiendo la canastilla; y quien ofrece la joven a Escipión ocupa ahora el lugar de la doncella negra en el cobre de Willemsens. En el fondo se omite la arquitectura y el cortinaje. Es evidente que esta composición tuvo éxito en la pintura de género de este pintor, de quien, por fortuna, vamos localizando obras documentadas en España ${ }^{17}$.

La misma composición vamos a verla con variantes en distintos pintores, lo que se presta a confusiones difíciles de hilar. Además de la pintura de Erasmus Quellinus mencionada, existen otras variantes con compleja atribución. Una a nombre de Theodor Boeyermans registra Hairs, aunque con reservas, en la monumental obra que le dedicada a los discípulos de Rubens ${ }^{18}$.

\footnotetext{
15 De Marchi y Van Miegroet, "Uncertainty, family ties", pp. 65-67.

${ }^{16}$ Sotheby's, (04/12/2008). Hoy se encuentra en una colección privada de Madrid.

17 A través de los marchantes Musson y Forchoudt. A propósito de la relación de estos marchantes con A. Willemsens, véase Jean Denucé, Exportation d'œuvres d'Art au $17^{\text {ème }}$ siècle à Anvers. La Firme Forchoudt, (Anvers: De Sikkel, 1931), pp. 66-68, 69, 70-74, 78-80, 85-87, 89, 132, 137, 165, 282-283, 287; Jean Denucé, Na Peter Pauwel Rubens. Documenten in Kunsthandel te Antwerpen in de XVII eeuw van Matthisjs Musson, (Antwerpen: De Sikkel, 1949), p. 197; Sanzsalazar, "Identificada una pintura de Abraham Willemsens", p. 264.

18 Marie-Louise Hairs, Dans le sillage de Rubens : les peintres d'histoire anversois au XVIIe siècle, (Liège : Université de Liège, 1977), p. 261. Aparece como posible obra de Boeyermans.
} 


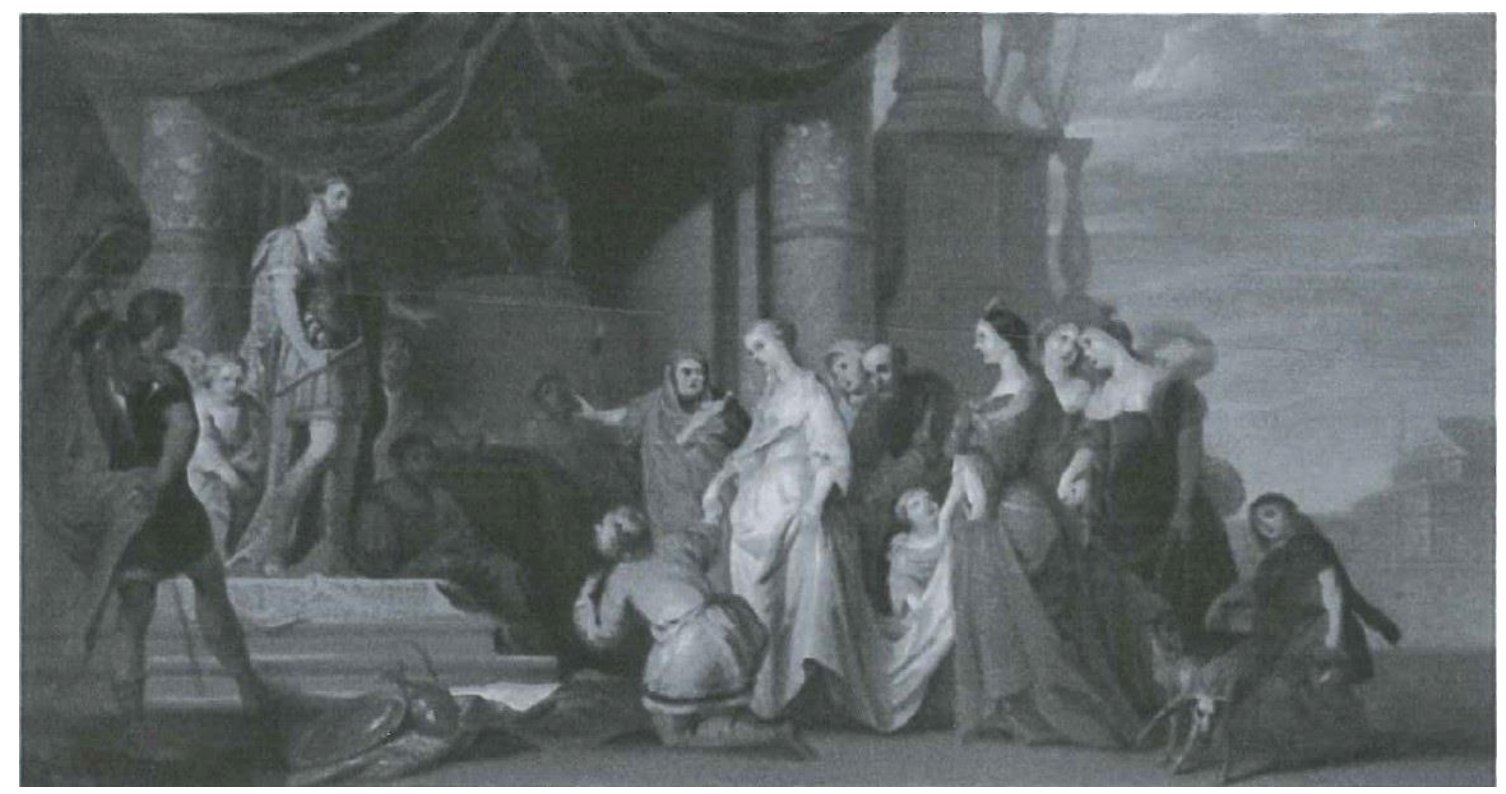

Fig. 6. Erasmus Quellinus, La continencia de Escipión. (Óleo sobre cobre). @ Cortesía de Sotheby's

Sin embargo, las características de la obra nos llevan a pensar en el peculiar estilo de Willem Van Herp, cuyos modelos son muy típicos suyos. Es la misma obra que aparece también atribuida a Boeyermans en el mercado artístico londinense de $1992^{19}$ (o/l., 138 × $205 \mathrm{~cm}$ ); y con la misma atribución en la galería Hartveld de Amberes (Fig. 8). La novedad respecto al cobre de Abraham Willemsens está en la joven doncella con la cestilla que vuelve su rostro hacia la princesa y la mayor proximidad al palacio con pórtico destacado a la derecha. La joven más distinguida está aquí de espaldas, y en diálogo directo con el suceso al adelantar su mano izquierda, todos estos cambios se deben a la revisión del tema por Willem Van Herp.

Otra repetición de menor tamaño ${ }^{20}$ (o/l., 115 x $160 \mathrm{~cm}$ ), también atribuida a Theodor Boeyermans, omite el pórtico y el obelisco, pero reproduce la arquitectura del lado derecho y el plinto con pavo real en primer plano. Una tercera versión de menor calidad se conserva en el Museo de La Rioja en Logroño (.$^{0}$ inv. 448) recogida como anónimo flamenco ${ }^{21}$ (o/c. 70 x $86 \mathrm{~cm}$ ); (Fig. 10). Al pertenecer a una serie de seis cobres, algunos de ellos firmados por Guillermo Forchondt, se ha propuesto el nombre de este artista para todo el conjunto, incluido el de Moisés salvado de las aguas ${ }^{22}$, sin embargo, Van Gingogen ya apunta a la intervención de más de un pintor en la serie ${ }^{23}$. De

\footnotetext{
${ }^{19}$ Londres, Sotheby's, (9-12-1992, n. $\left.{ }^{\circ} 242\right)$.

${ }^{20}$ Amsterdam, Sotheby's, (12-6-1979, n. o 2017).

21 José Francisco Forniés Casals, "El Museo de Logroño. Notas acerca del Arte en los Cameros y en La Rioja", en Francisco Abbad Ríos, a su memoria, (Zaragoza: Universidad de Zaragoza, 1973), p. 92.

22 Sandra Van Ginhoven, Connecting Art Markets. Guilliam Forchondt's Dealership in Antwerp (ca. 16321678) and the Overseas Painting Trade, (Leiden-Boston: Brill, 2017), p. 197, (Fig. 6.15).

${ }^{23}$ Van Ginhoven, Connecting Art Markets, p. 196. Sobre el trabajo de varios maestros dentro de la producción para Guillermo Forchondt y la diversidad de manos, a pesar de incluir la firma en muchas de las obras, véase: Ana Diéguez-Rodríguez, "Las pinturas sobre cobre el mercado artístico de la Edad Moderna. A propósito de los cobres del taller de Guillaume Forchondt en la catedral de Jaén", en La Catedral de Jaén a examen II. Los bienes muebles en el contexto internacional, coord. Pedro A. Galera Andreu y Felipe Serrano Estrella, (Jaén: UJA editorial, cátedra Andrés de Vandelvira, 2017) pp. 174-175.
} 


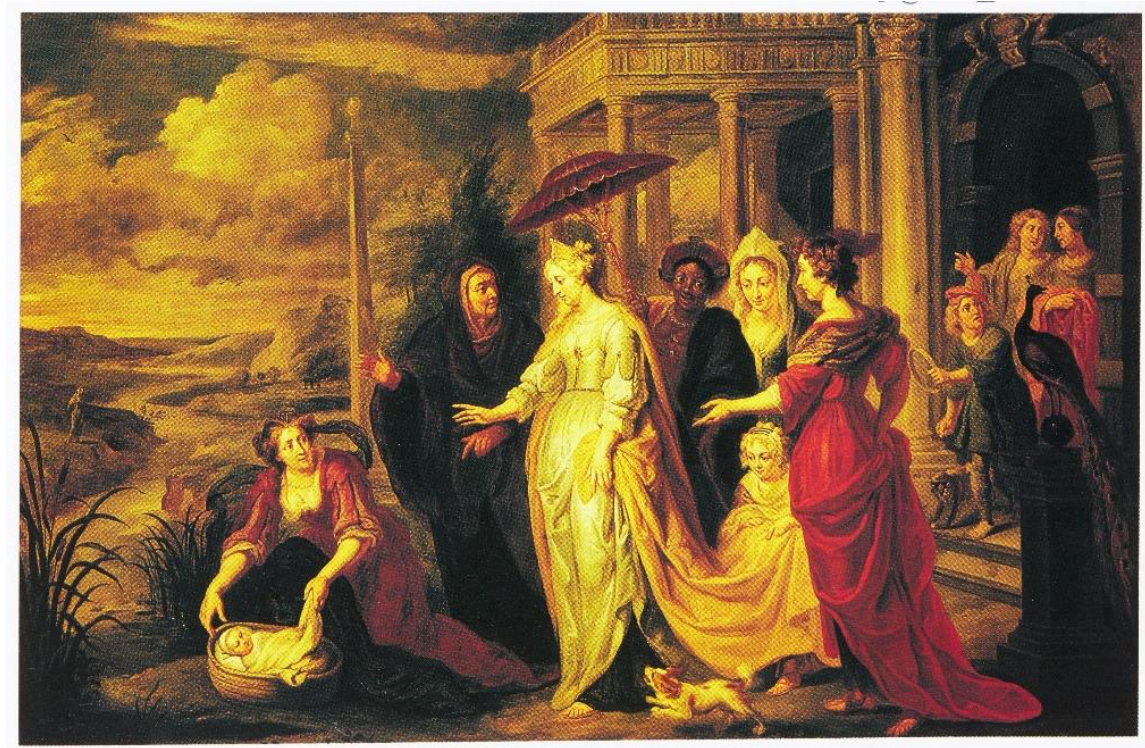

Fig. 7. Willem van Herp, Moisés salvado de las aguas. (Óleo sobre lienzo). @ Cortesía de Sotheby's

hecho, esta obra de La Rioja pensamos está más próxima al estilo de Abraham Willemsens, pintor muy activo con los círculos comerciales de los Musson, Fourmenois y los Forchondt en Amberes como ya se ha comentado ${ }^{24}$.

Esta serie del museo riojano procede del convento de la Santísima Trinidad de Logroño, como me ha hecho saber Teresa Álvarez González y a la que agradezco la información. La serie se recoge en el inventario de bienes realizado tras la desamortización del convento en 1835, que trascribe Layna Serrano ${ }^{25}$. En el listado aparecen diez cobres, de los que seis pasan al Instituto de Enseñanza Media de la ciudad en 1963, ingresando en el museo en 1971.

Finalmente, otra repetición prácticamente idéntica, pero de mayor tamaño (o/c. $87 \times 140 \mathrm{~cm}$ ), estuvo en el mercado madrileño con atribución a Abraham Willemsens ${ }^{26}$; y otra de menor calidad, es la copia en el SintElisabethziekenhuis de Lier $(162 \times 223 \mathrm{~cm})$.

Como se puede ver, la composición ideada por Abraham Willemsens tuvo éxito y fue repetida no sólo en su propio taller en múltiples ocasiones, sino también versionada por otros artistas en la misma órbita para el mercado internacional como Erasmus Quellinus y Willem van Herp ${ }^{27}$. La tipología de sus personajes, de canon corto y cabeza pequeña; rostros redondos de mejillas anchas donde destacan los ojos de modelado más duro; y el gusto por los reflejos de la luz sobre los tejidos y materiales asociables al espíritu de Veronés, responden a la misma sensibilidad en todas las obras.

\footnotetext{
${ }^{24}$ Véase nota 2.

${ }^{25}$ Francisco Layna Serrano, "Noticias documentales sobre conventos antiguos de la ciudad de Logroño", Berceo, 1, (1946), p. 47.

${ }^{26}$ Madrid, Ansorena, (6/3/2012, n.0 436).

27 Sobre la confusión de la obra de Abraham Willemsens y Willem van Herp y el trabajo conjunto para el mercado de ambos, véase Sanzsalazar, "Identificada una pintura", p. 264.
} 


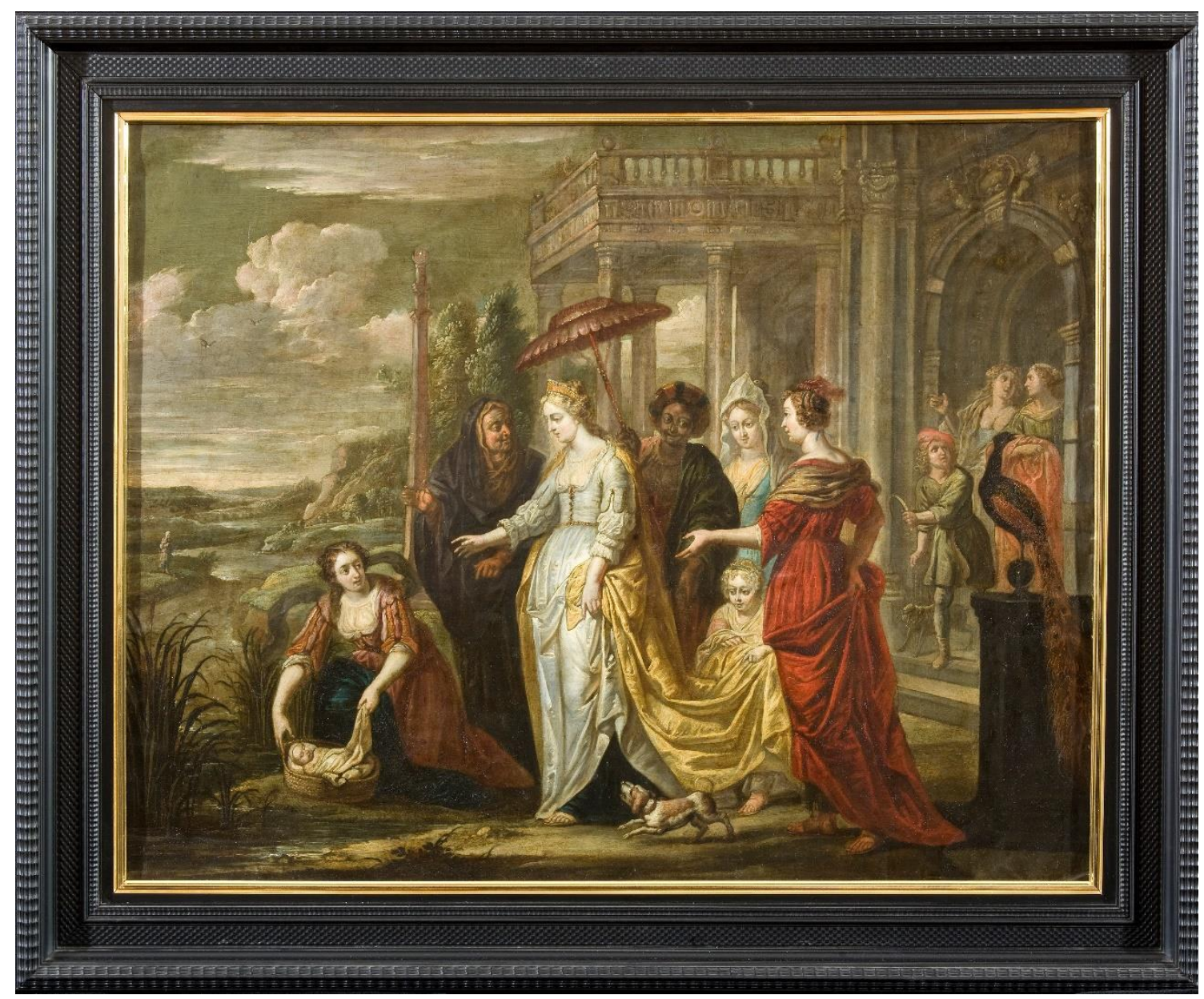

Fig. 8. Abraham Willemsens, Moisés salvado de las aguas, c. 1650. (Óleo sobre cobre). (C) Museo de la Rioja,

Logroño (inv. n. ${ }^{\circ} 448$ ).

La personalidad artística de Abraham Willemsens ha sido enredada y diluida por el tiempo, a pesar de ser un artista muy productivo en su momento. La confusión de su trabajo con otros colegas de su entorno al repetir composiciones, y la concordancia de las iniciales de su nombre con el de otros pintores flamencos del siglo XVII ha acentuado esa mezcla de estilos que esperamos que este trabajo ayude a esclarecer. 
Apéndice documental:

Se incluye aquí parte del análisis de pigmentos realizado al cobre Moisés salvado de las aguas ${ }^{28}$, por si su difusión puede ayudar a estudios posteriores en relación con su taller y materiales empleados.

\begin{tabular}{|c|c|c|c|c|}
\hline Capa & Color & $\begin{array}{l}\text { Espesor } \\
(\mu \mathrm{m})\end{array}$ & Pigmentos / cargas & Observaciones \\
\hline 5 & Traslúcido & $\sim 20$ & - & Barniz \\
\hline 4 & Azul & $10-20$ & $\begin{array}{l}\text { Azurita, albayalde, } \\
\text { pigmentos de tierra } \\
\text { (m. b. p.) }\end{array}$ & $\begin{array}{l}\text { Capa de } \\
\text { pintura }\end{array}$ \\
\hline 3 & Morado & $20-35$ & $\begin{array}{l}\text { Azurita, pigmentos de } \\
\text { tierra (b. p.), pigmento } \\
\text { laca rojo (m. b. p.), yeso } \\
\text { (m. b. p.) }\end{array}$ & $\begin{array}{l}\text { Capa de } \\
\text { pintura }\end{array}$ \\
\hline 2 & Blanquecino & $10-25$ & $\begin{array}{l}\text { Albayalde, pigmentos de } \\
\text { tierra (b. p.), carbón } \\
\text { vegetal (m. b. p.) }\end{array}$ & Imprimación \\
\hline 1 & Verde & $0-15$ & Cobre & $\begin{array}{l}\text { Adhesivo } \\
\text { aplicado sobre } \\
\text { el soporte }\end{array}$ \\
\hline
\end{tabular}

\begin{tabular}{|l|l|l|}
\hline \multicolumn{2}{|l|}{ Materiales identificados en las micromuestras } \\
\hline Color & Pigmentos / cargas \\
\hline $\begin{array}{l}\text { Blanco (opacos y } \\
\text { transparentes) }\end{array}$ & Albayalde & Carbonato cálcico \\
\cline { 2 - 3 } & yeso \\
\hline Azul & azurita \\
\hline
\end{tabular}

${ }^{28}$ Estudio realizado por Arte-Lab S. L., Análisis y Documentación de Obras de Arte, Apoyo Científico a la Restauración (25-06-2019). 


\begin{tabular}{|l|l|l|}
\hline Amarillo & $\begin{array}{l}\text { Amarillo de plomo y } \\
\text { estaño }\end{array}$ & Pigmento laca amarillo \\
\hline Anaranjado & Tierras & Minio \\
\hline Rojo & Pigmento laca rojo \\
\hline Negro & Carbón vegetal \\
\hline Materiales orgánicos \\
\hline Aceite sécate como aglutinante de las capas de pintura \\
\hline
\end{tabular}


Bibliografía:

De Marchi y Van Miegroet 2012: Neil de Marchi y Hans J. van Miegroet, "Uncertainty, family ties and derivative painting in seventeenth-century Antwerp", en Family Ties. Art Productions and Kinschip Patterns in the Early Modern Low Countries, ed. K. Brosens, L. Kelchtermans y K. van der Stighelen, (Turnhout: Brepols, 2012), pp. 53-74.

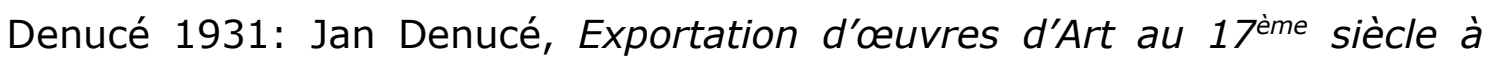
Anvers. La Firme Forchoudt, (Anvers: De Sikkel, 1931).

Denucé 1949: Jan Denucé, Na Peter Pauwel Rubens. Documenten in Kunsthandel te Antwerpen in de XVII eeuw van Matthisjs Musson, (Antwerpen: De Sikkel, 1949).

Díaz Padrón 2005: Matías Díaz Padrón, "Tres pinturas flamencas identificadas en México", Boletín del Seminario de Arte y Arqueología (BSAA arte), LXXI, (2005), pp. 163-173.

Diéguez-Rodríguez 2017: Ana Diéguez-Rodríguez, "Las pinturas sobre cobre el mercado artístico de la Edad Moderna. A propósito de los cobres del taller de Guillaume Forchondt en la catedral de Jaén", en La Catedral de Jaén a examen II. Los bienes muebles en el contexto internacional, coord. Pedro A. Galera Andreu y Felipe Serrano Estrella, (Jaén: UJA editorial, cátedra Andrés de Vandelvira, 2017, pp. 167-183.

Duverger 1968: Erik Duverger, "Nieuwe gegevens betreffende de kunsthandel van Matthijs Musson en Maria Fourmenois te Antwerpen tussen 1633 en 1681", Gentse Bijdragen tot de Kunstgeschiedenis en de Oudheidkunde, 21, (1968), pp. 5-250.

Duverger 2002: Erik Duverger, Antwerpse Kunstinventarissen uit de Zeventiende Eeuw, Fontes Historiae Artis Neerlandicae, 12, (Brussel: Koninklijke Vlaamse Academie van België voor Wetenschappen en Kunsten, 2002), pp. 106-107.

Forniés Casals 1973: José Francisco Forniés Casals, "El Museo de Logroño. Notas acerca del Arte en los Cameros y en La Rioja", en Francisco Abbad Ríos, a su memoria, (Zaragoza: Universidad de Zaragoza, 1973), pp. 77-99.

Hairs 1977 : Marie-Louise Hairs, Dans le sillage de Rubens: les peintres d'histoire anversois au XVIIe siècle, (Liège : Université de Liège, 1977).

Layna Serrano 1946: Francisco Layna Serrano, "Noticias Documentales sobre conventos antiguos de la ciudad de Logroño", Berceo, 1, (1946), pp. 9-58.

Martin 1991: Gregory Martin, "The Maître aux Béguins. A proposed identification", Apollo, CXXXIII, 348, (1991), pp. 112-115.

Martin 1993: Gregory Martin, "Abraham Willemsens (again). More news of attributions in Flemish painting", Apollo, CXXXXII, 372, (1993), pp. 97-102. 
Roethlisberger 1988: M. Roethlisberger, "Le peintre Abraham Willemsens", Jaarboek van het Koninklijk Museum voor Schone Kunsten Antwerpen, (1988), pp. 253-259.

Rombouts y Van Lerius 1872: Ph. Rombouts y Th. Van Lerius, De Liggeren en Andere Historische Archieven, II, (Gravenhage: Martinus Nijhoff, 1872).

Sanzsalazar 2008: Jahel Sanzsalazar, "Identificada una pintura de Abraham Willemsens con atribución a Willem van Herp", Boletín del Museo e Instituto Camón Aznar, 101, (2008), pp. 259-267.

Valdivieso 1986: Enrique Valdivieso, "Dos pinturas de Abraham Willemsens en el Museo del Prado y otras obras de este pintor en España", Boletín del Museo del Prado, VII, 21, (1986), pp. 166-172.

Van Ginhoven 2017: Sandra van Ginhoven, Connecting Art Markets. Guilliam Forchondt's Dealership in Antwerp (ca. 1632-1678), (Antwerp: Brill, 2017).

Werche 2004: Bettina Werche, Hendrick van Balen (1575-1632). Ein Antwerpener Kabinettbildmaler de Rubenszeit, (Belgium: Brepols, 2004).

Recibido: 25/03/2021

Aceptado: $28 / 04 / 2021$ 